\title{
Dignidad en el Acto de Morir: ¿Moral o Derecho?
}

\author{
Por: JULIÁN ADOLFO RUIZ MORALES \\ Abogado especialista en Derecho Administrativo \\ Secretario Académico de Derecho y Ciencias Sociales - \\ CORPORACIÓN UNIVERSITARIA DEL META
}

"Es imposible que una cosa tan natural, tan necesaria y tan universal como la muerte pueda haber sido destinada a la humanidad, por la providencia, como un mal".

\section{Jonathan Swift}

Escritor y político irlandés.

Es complicado encontrar situaciones y vivencias tan connaturales al ser humano como la muerte y que al mismo tiempo se evite tanto en el diario vivir. Muy pocas personas meditan sobre el fin de sus días, salvo que se esté enfermo o entrado en años, la mayoría evadimos el tema, lo ignoramos hasta que toca a nuestra puerta o visita a un ser querido.

En culturas como la nuestra, la muerte está rodeada de un halo de miedo, de terror a lo desconocido y de sufrimiento por la separación; omitiendo la posibilidad que brinda perpetuarse y trascender.

Nuestra posición ante la parca depende en gran manera de nuestras creencias y nivel educativo, pues ellas nos acercan más al análisis de los fenómenos que rodean nuestro diario devenir, desde luego nos enfrenta al propio final de nuestras vidas y la pregunta capital acerca del más allá.

Las afirmaciones precedentes son el introito para mencionar que la muerte se relaciona con creencias religiosas y culturales; como por ejemplo la existencia de una deidad y la trascendencia del alma humana, sin embargo este artículo pretende alejarse de estos ámbitos y por el contrario busca abordarla desde un plano más objetivo y general.

\section{Diversos conceptos de muerte}

Descartando el aspecto religioso y centrándonos en lo meramente biológico, anteriormente la determinación de la muerte no revestía mayores problemas; se limitaba a establecer la cesación de las funciones cardiaca y respiratoria por métodos más o menos rudimentarios.
El paro cardiorrespiratorio era determinante para establecer el fallecimiento del ser humano, sin atender su etiología. Esta simpleza no estaba exenta de inconvenientes derivados de la dificultad de detectar signos vitales bajos por patologías y otras muchas causas de fenómenos catalépticos, de las que se derivan las creencias y mitos acerca de inhumaciones en vida.

Con el desarrollo de la ciencia médica se ha eliminado lo empírico de la determinación de la muerte y se ha reducido a casi cero la posibilidad de confundirla con cualquier patología; este mismo desarrollo nos ha llevado al avance de las técnicas de cuidado intensivo que hoy permiten preservar artificialmente la función cardiorrespiratoria y aún más, se pueden reemplazar los órganos por artilugios; con lo que establecer el momento de la muerte se complica en grado sumo.

Ahora sabemos que cada ser humano vive varias muertes en una sola; muertes que se suceden unas a otras y hasta muertes que le preservan la vida, muertes que suceden cada día y algunas que acontecen una sola vez; pero todas ellas ligadas estrechamente e inescindiblemente a la vida.

El añejo concepto de fallecimiento ya no es suficiente para abordar el tema de la dignidad a la hora de partir de este mundo; tendremos que afrontar conceptos complejos como las muertes celular, tisular, orgánica, cerebral, total y las condiciones que las adjetivan, entre otras la eutanasia, distanasia, ortotanasia y suicidio.

Podríamos estar tentados a considerar los fenómenos mencionados como simples entelequias o elucubraciones, pero nada más lejos de la realidad, sobre todo en lo que atañe a la muerte en condiciones dignas.

Trataremos de simplificar estos conceptos a fin de profundizar en el concepto de muerte digna y su relación más o menos cercana con la moral o el derecho. 


\section{ISSN-2248-736 * Número 3 * Revista Facta Non Verba}

La muerte convive, cohabita y es fundamental para preservar la vida; ejemplo de ello es la muerte celular. Las células mueren constantemente como reacción a lesiones físicas, daño genético, privación de oxígeno o nutrientes, pérdida de contacto con las células vecinas o infección.

El proceso de muerte celular, técnicamente apoptosis, es un proceso natural estrictamente regulado fisiológicamente que permite el desarrollo, mantenimiento y reparación de los tejidos y consecuencialmente de los órganos y las funciones que ellos cumplen para preservar la vida.

Por ejemplo, podemos mencionar que la falla en este proceso de muerte celular desencadena la proliferación de células defectuosas que se convierten en tumores. Sobra decir que éste proceso no pone en riesgo, per se, la sobrevivencia; al contrario, la prolonga en el tiempo.

La muerte tisular es similar a la celular, de hecho muere una mayor cantidad de células lo cual deriva en la muerte de un tejido y en algunos casos comporta la pérdida de una función o un órgano. Es conocida más técnicamente como necrosis tisular y a diferencia de la muerte celular, no es un mecanismo de defensa o protección; es una pérdida originada por patologías de múltiple etiología, lesiones o procesos isquémicos.

La muerte tisular pone en riesgo la vida, cuando su magnitud afecta la función del tejido afectado. El infarto agudo de miocardio es un ejemplo de este fenómeno; de acuerdo a la magnitud de la isquemia y a la extensión del daño sufrido por el tejido cardiaco, permitirá o impedirá la vida de quien la padece.

La muerte tisular puede desencadenar la muerte orgánica, que consiste en la cesación permanente de la función de un órgano, el cual se encamina a la necrosis total del mismo. Se concluye entonces que las clases de muerte mencionadas corresponden a la magnitud del daño que ellas representan en la funcionalidad del paciente.

En relación directa con la importancia de la función del órgano muerto, puede desencadenarse la muerte clínica o la muerte cerebral o neurológica. En el caso de órganos pares o cuya función no es vital, el paciente continuará vivo, aunque sufra limitaciones.

Hasta acá no existe mayor dificultad para afrontar estos conceptos, tan escuetamente presentados; aunque realmente a nivel científico son complejos y colmados de reacciones bioquímicas.

Venimos ahora a tratarde comprender algunos de los escenarios que realmente complican ética, moral y legalmente entender la muerte.

Al inicio de estas líneas citamos la definición de muerte generalmente aceptada hasta los años cincuenta del siglo pasado, la que implicaba el cese irreversible de las funciones cardiaca y respiratoria sin posibilidad de reanimación; estos elementos son los que hoy día aún se aceptan bajo el concepto de muerte clínica.

Como ya enunciamos, la ciencia médica ha permitido que hoy en día las funciones cardiaca y respiratoria puedan suplirse con artilugios, lo que elimina o desdibuja estos dos elementos como trascendentales para determinar el deceso.

La moderna realidad tecnológica de suplir funciones orgánicas vitales, conlleva a la posibilidad de interferir indefinidamente el momento de la cesación definitiva de los fenómenos bioquímicos que sustentan la vida; ésta nueva situación es denominada distanasia y puede derivar en ensañamiento, encarnizamiento terapéutico u obstinación médica, cuando los procedimientos exceden los protocolos normales o cuando los procedimientos médicos tienen pretensiones diagnósticas o terapéuticas que en nada mejoran la situación del enfermo o le causan sufrimiento innecesario.

La distanasia en cierta manera es auspiciada por el concepto culturalmente aceptado de que "mientras hay vida hay esperanza", lo que en la mayoría de los casos es científicamente desvirtuable; en muchas ocasiones encuentra asidero en el deseo de los familiares y allegados del enfermo que abrigan esperanzas u oponen sus creencias a la realidad médica.

La distanasia siempre encontrará defensores y justificaciones, no así el ensañamiento, encarnizamiento terapéutico u obstinación médica; pues obedece generalmente a motivos innobles como el déficit de competencia del galeno o la desviación de la visión del paciente como fin de la medicina, hacia otros intereses políticos, científicos, económicos, entre otros.

Ahora bien, si no es aplicable la cesación de la función cardiorrespiratoria para determinar la muerte, ¿Qué consideraciones podremos tomar en cuenta?; la respuesta surge desde la misma ciencia médica y se conoce como muerte encefálica.

En 1968 la Facultad de Medicina de la Universidad de Harvard adoptó la muerte encefálica como criterio para determinar la muerte, basándose en las funciones y estructura propia del cerebro. 
Muy esquemáticamente podemos esbozar las funciones cerebrales diciendo que la corteza cerebral o cerebro superior es responsable de nuestra vida consciente; por su parte, el tallo cerebral cumple dos funciones: Tiene a su cargo la vida orgánica y además sirve de conexión obligatoria entre el cerebro superior y el resto del cuerpo. El tálamo y el hipotálamo conforman el diencéfalo, y en ellos reside la vida sensorial y motriz.

Estas funciones cerebrales son relativamente autónomas las unas de las otras, circunstancia que permite que una parte del cerebro muera y otra siga viviendo; con esta particularidad, la muerte encefálica que se presentaba como solución al problema de definir la muerte, ya no lo es tanto.

Como contrapunto, Bernat y "La Comisión Presidencial de los Estados Unidos", proponen la necesidad de la muerte total del cerebro para diagnosticar inequívocamente la muerte.

Las posturas precedentes muestran como el tema no se simplifica, pero la cosa no para allí, existe una tercera postura más problemática aún y que es abanderada por algunos médicos y bioeticistas; plantea como momento de deceso, la muerte del cerebro superior, aún quedando vivo el tallo cerebral.

Muchas galenos, unos más abiertamente que otros, comparten la postura liderada por el doctor Robert Veatch, director del Centro de Bioética de la Universidad de Georgetown en Washington, quien sostiene que en este caso muere la persona, cuya sede es el cerebro superior, pero le queda un poco de movimiento en su organismo, como los ojos, la respiración autónoma, y los latidos del corazón.

Desde la Bioética se sostiene que en estos casos la persona ya está muerta pero queda en estado vegetativo persistente, irreversible. Nunca podrá volver a vivir y a obrar como persona. Sencillamente ya murió.

\section{El dilema sobre qué es vivir.}

Continuando por la línea que venimos, podría considerarse la vida desde varias ópticas; desde la aparentemente elemental que define la vida como el intermedio entre el nacimiento y la muerte, o la marcadamente sicológica que establece que es un sentimiento apreciativo por las interacciones del ego con el medio y la lucha por mantener la homeóstasis derivada de dicho sentimiento.
El concepto de vivir es algo más complejo, elaborado y recompensante que solo agotar días en este planeta o mantener unas constantes vitales que prueben el adecuado funcionamiento orgánico. Se trata de interactuar con los demás y con el entorno, crear relaciones, influir positivamente en la vida de los demás para enriquecer la propia.

Pasar por la vida sin pena ni gloria, dejar pasar los minutos sin dejar huella en la historia de alguien más o limitarse a escribir la propia de manera aislada, no es vivir, es simplemente existir. Es cierto que podemos conformarnos simplemente con existir, renunciar voluntariamente a tener sueños, planes, sentimientos y vivencias; pero mientras se conserve la posibilidad real de gozar y no solamente de respirar, aún queda vida.

Estas afirmaciones nos podrían llevar a una larga disquisición que no se abordará ahora, pues no es el motivo principal de estas líneas; basta por ahora decir que la diferencia entre vivir y existir es la posibilidad real de sentir y expresar afectos, relacionarse, trascender.

Lo precedente puede parecer irrelevante, pero veremos que es de vital importancia al abordar dilemas morales que se plantearán a continuación.

Ahora bien, a la mayoría de las personas no nos basta existir; ni siquiera vivir, lo adjetivamos aún más agregándole un concepto más subjetivo: La dignidad.

Tratar de definir la dignidad es muy difícil, es un concepto influenciado por el propio autoconcepto y autoestima, la educación, los principios y valores, el entorno en que nos desarrollamos y una amplia lista de muchos otros factores, sin dejar de lado la posibilidad de mejorar la existencia mediante la toma de decisiones y el ejercicio de la libertad.

El concepto de dignidad está íntimamente ligado al ser humano, desde la óptica del derecho y las ciencias sociales cobra capital importancia, pues se ha tratado de objetivarlo incluyéndolo en los documentos fundacionales de la mayoría de los estados, en la Declaración Universal de los Derechos Humanos y en su normatividad regulatoria, también en el derecho internacional humanitario.

Por ahora digamos que la dignidad es posible en la medida en que podamos tomar las decisiones necesarias para que nuestra vida corresponda a nuestros valores, deseos y anhelos en la medida necesaria para respetarnos y recibir respeto de parte de nuestros congéneres. 
ISSN-2248-736 * Número 3 * Revista Facta Non Verba

\section{La muerte, hecho $o$ acto jurídico.}

El hecho jurídico es un acontecimiento natural, que sucede sin que medie la voluntad y que tiene implicaciones o efectos jurídicos; en contraposición, el acto jurídico implica una manifestación de la voluntad en procura de alcanzar la consecuencia jurídica prevista por la ley.

Ala luz de la sucinta definición precedente, podemos afirmar que en términos generales la muerte es un hecho jurídico, pues no es usual que tengamos la posibilidad o tomemos la opción de decidir cómo y cuándo falleceremos.

Pero, ¿qué sucede con aquellas oportunidades en que podemos decidir las circunstancias que rodearán nuestro deceso?

El ser humano vive con la certeza de que morirá en algún momento, pero por diversas razones evitamos pensar en ello, esta omisión encuentra asidero en el hecho de que en la mayoría de los casos no tenemos manera de dar fecha cierta a la ineludible cita; en algunas ocasiones fallecemos sin siquiera tener tiempo de darnos cuenta de ello. Pero existen oportunidades en que la vida misma, la providencia, el gran arquitecto, la suerte o como se quiera llamar, nos enfrenta a la certeza de morir en un lapso de tiempo determinado.

Ante la certeza de morir en corto tiempo o en fecha más o menos cierta, algunas personas dejan en manos de esa misma providencia lo que ha de acontecer; pero otras optan por tomar las riendas de los acontecimientos y decidir cómo ha de ser su partida.

Ante ésta toma de control de las circunstancias de tiempo, modo y lugar en que ha de acontecer la defunción, no queda opción diferente a pensar que el elemento aleatorio pasa a un segundo plano y es la voluntad de la persona la que determinará lo que habrá de acontecer, en este caso se habla entonces de la muerte como acto jurídico.

Existe otra premisa que merece análisis como contentiva de elementos que tornarían la muerte en un acto jurídico; la defendida por las asociaciones que propugnan por el derecho a morir dignamente. Esta consiste en la posibilidad de suscribir, divulgar y hacer oponible a terceros su voluntad expresa y escrita de no recibir medidas y tratamientos médicos extraordinarios en caso de enfermedades intratables, patologías incurables en estado terminal o lesiones cerebrales que comprometan gravemente la autonomía personal; documento que se suscribe aún estando sano.
Desde éstas ópticas, es predicable que en algunas circunstancias especiales la muerte no es un hecho jurídico.

\section{Laimportancia delamuerte enlahistoriayla recordación.}

La vida hace parte de la muerte. El Sacerdote Alfonso Llano Escobar S.J en algunos de sus escritos sobre la muerte ha incluido frases célebres, que ilustrarían esta afirmación con mediana claridad "cada quien vive su propia muerte y muere su propia vida" o "la muerte es el precio que se paga por haber vivido".

En la actualidad, la muerte está muy devaluada, antaño y aún en otras culturas contemporáneas, la mayoría de ellas no occidentales, la parca se reconoce, se acepta, se respeta, se venera y hasta se aprecia.

La vida es como una obra de teatro, un libro o una película: Puede tener una trama y un desarrollo excelente arruinado por un pésimo final; o ser pobre en contenido y pasar a la posteridad gracias a un brillante final.

Muchas vidas anodinas, mustias, tristes e históricamente insignificantes han trascendido por una muerte heroica, digna o destacable.

Ejemplos hay muchos; citemos a Antonio Ricaurte Lozano (Villa de Leyva, 10 de Julio de 1786 - San Mateo, 25 de Marzo de 1814), quien vivió siendo un criollo acomodado, un oficial de nivel inferior; pero se catapultó a la historia al momento de morir, inmolándose para evitar que un polvorín callera en manos de los españoles.

Para comprobar en algo la veracidad de esta afirmación de la muerte como última oportunidad de perpetuarse en la historia o cuando menos en el recuerdo, se indagó en el Decanato por un personaje del común que se hubiese inscrito en la historia por una muerte heroica. La respuesta fue un nombre inesperado: José Antonio Galán.

José Antonio Galán fue un mestizo agricultor nacido en Charal en 1749 y ejecutado el 1 de febrero de 1872 en Santafé de Bogotá, célebre por su participación en la insurrección de los comuneros y por lo atroz de su ejecución.

Este personaje, en el imaginario de varias personas, además de haber sido confundido inicialmente por el líder liberal Luis Carlos Galán, es recordado por haber sido descuartizado, sin embargo ninguno recordó que hizo en la gesta comunera y mucho menos que buscaba la misma. 
Esta situación es una prueba sumaria de como "in articulo mortis" una vida gris e intrascendente históricamente, puede brillar para la posteridad.

So pena de herir susceptibilidades surge la siguiente cuestión: ¿Qué sería de la epopeya de la salvación de la humanidad, la derrota de la muerte y el pecado por el suplicio de Cristo en la cruz, pilar de todas las religiones judeo cristianas?

De igual forma, una vida destacable pierde brillo al concluir con una muerte indecorosa, a tal punto que personajes como Miguel Ángel Osorio Benítez, nacido en Santa Rosa de Osos el 29 de Julio de 1883 y fallecido en Ciudad de México el 14 de Enero de 1942, más conocido como Porfirio Barba Jacob, llego a manifestar mientras moría de tuberculosis: "Presento disculpas por ésta agonía tan poco gallarda”.

En igual sentido podemos citar muertes que a más de indecorosas resultan hasta escatológicas, como la muerte de Heráclito, uno de los grandes filósofos griegos, quien murió voluntariamente cubierto de boñiga de buey a sus 60 años.

Así las cosas, es claro que en el ideario popular la muerte sigue marcando el grado de recordación de las personas; es por ello que resultaría adecuado y admisible, desde ninguna óptica, que se pretenda regular la manera en que debemos afrontar la muerte.

Así las cosas, es claro que lo que privilegia la constitución es la posibilidad de vivir con dignidad, admitiendo la singularidad que dicho concepto entraña; en forma alguna consagra la vida como una obligación y mucho menos posibilita que el Estado en forma alguna pueda ejercer coacción para que el ciudadano deba vivir a toda costa.

El ser humano es el titular del derecho a la vida y como tal tendría el derecho de disponer de él, sin más consideración que sus propios principios morales y su propio concepto de dignidad; un asomo en éste sentido se pronunció por la corte en sentencia T-493/93 con ponencia del Magistrado Antonio Barrera, cuando se abordó el tema del derecho a elegir si se enfrenta la muerte o se prolonga la existencia por medio del tratamiento médico, prevaleciendo la tesis de que solo el titular del derecho a la vida es quien decide hasta qué punto ella es compatible con la dignidad humana.

La sentencia C-239/97 con ponencia de Carlos Gaviria Díaz, establece que "El deber del Estado de proteger la vida debe ser entonces compatible con el respeto a la dignidad humana y al libre desarrollo de la personalidad". Paralelamente y de manera más directa expresa "El derecho fundamental a vivir en forma digna implica entonces el derecho a morir dignamente, pues condenar a una persona a prolongar por un tiempo escaso su existencia, cuando no lo desea y padece profundas aflicciones, equivale no sólo a un trato cruel e inhumano, prohibido por la Carta (CP Art.12), sino a una anulación de su dignidad y de su autonomía como sujeto moral. La persona quedaría reducida a un instrumento para la preservación de la vida como valor abstracto".

Es por estas razones, entre otras muchas, que el derecho sancionatorio colombiano no establece pena alguna para el suicida fallido; no podría hacerlo, pues está disponiendo

libremente de su derecho a existir. Se sanciona a quien induce, instiga o ayuda a otro a poner fin a sus días, pues se considera que esa conducta vicia el consentimiento del suicida y al homicida pietístico, aunque lo trata con benevolencia.

Resulta claro a todas luces, que siendo la muerte parte integral de la vida, también sería licito decidir cómo y cuándo acontecerá, máxime si las circunstancias de la vida, Dios, la suerte o como se le quiera llamar, nos ha permitido conocer tentativamente la fecha de expiración de nuestro paso por la tierra y las condiciones que han de rodear nuestra partida.

Sin estar en contra de la fe, sin negar las curaciones milagrosas, la sanación o cualquier otra posibilidad de recuperar la salud; puede considerarse totalmente válido y viable obviar el dolor, el sufrimiento y los padecimientos innecesarios ante una muerte inminente.

Para algunos puede parecer muy heroico y hasta fuente de salvación, someterse a los dolores y padecimientos de una enfermedad; para otros puede ser dignificante someterse a tratamientos extraordinarios, experimentales y de prolongación de la vida; para otros rechazarlos es lo propio y es dejar que la naturaleza siga su curso o la providencia decida.

Todas las posiciones tomadas a la luz de las propias creencias son absolutamente respetables y no deben ser objeto de censura alguna por el Estado, cuando de personas capaces legalmente se trate; más aún, no se debería ni siquiera limitar por vía de reglamentación, pues corresponde al fuero interno de cada persona, a su libre albedrío. 
ISSN-2248-736 * Número 3 * Revista Facta Non Verba

A partir de estos postulados resultaría entonces improcedente no sólo el rechazo de tratamientos que ya regula el Código de Ética Médica, sino también las decisiones en contra de la distanasia y aún el suicidio asistido. Más discutible sería lo atinente a la eutanasia pasiva o activa, pues comporta matar o dejar morir a otra persona, pero se justificaría si hay manifestación expresa y legalmente valida de la voluntad del enfermo, siendo éste plenamente capaz.

Esta postura implica no soltar las riendas de la propia vida hasta lograr la meta, pues cada quien es dueño de su vida y a nadie más atañe como quiere vivirla, aún en su minuto postrero; esto es cambiar el simple hecho natural de fallecer por la decisión autónoma de cómo y cuándo debe sobrevenir.

Ejemplos de dignidad al morir y de resolución para afrontar la muerte inminente abundan. Sócrates, quien se aseó para evitar la molestia a las mujeres que deberían hacerlo después de su muerte; bebió un veneno y al sentirse desfallecer se acostó dignamente. El Cacique Tundama quien al ser derrotado en 1539 por el capitán Baltazar Maldonado en las llanuras pantanosas de Duitama, prefirió morir a martillazos antes que doblegar sus principios al yugo español y Sigmund Freud, inventor del psicoanálisis, víctima de un cáncer de garganta y con treinta y tres intervenciones sin éxito, suplicó a su médico, Max Schur, que no lo dejara sufrir más y que le permitiera llegar a su fin. Una buena dosis de morfina intravenosa atendió a su reclamo.

\section{Unas consideraciones finales.}

Es necesario reconocer que la reglamentación referente a eutanasia y muerte digna se hace necesaria en los casos en que el paciente no ha manifestado su expresa voluntad de manera válida, caso de los enfermos terminales que han entrado en inconciencia o aquellos que sufren patología de cualquier índole que los ha sumido en coma profundo irreversible.

Retomamos la idea de que la muerte del cerebro superior, sede de las funciones cognitivas, al privar irremediablemente de la posibilidad de vida consciente, de relacionarse con el entorno y de interactuar con los congéneres, se debe considerar como muerte; pero aunque apoyado en éstas consideraciones el neurocirujano podría diagnosticar la muerte encefálica, los familiares ven al difunto respirar, su corazón palpita y les hace creer que está vivo y que hay esperanzas de que recobre su vida consciente.

Es aquí donde se debe reglamentar, en subsidio de lo que no hizo el propio paciente cuando pudo, para con ello aclarar el panorama y aliviar la carga de los parientes a la hora de decidir e incluso, dar plena validez y oponibilidad a las declaraciones de voluntad del paciente.
No permitamos que con nuestros parientes se repitan casos como el de la norteamericana Karen Quinian, que permaneció en estado vegetativo desde abril de 1975 hasta julio de 1985; o con Elaine Esposito, quien en 1941 entró en estado de inconsciencia luego de haber recibido anestesia para una cirugía y vino a morir en 1978, es decir, 37 años después, sostenida todo este tiempo de manera artificial.

Los casos mencionados son excepcionales, pero basta que la agonía se prolongue artificialmente unos pocos días, para que ya se esté atentando contra el derecho a una muerte digna; pues algunos médicos intensivistas olvidan a veces que las dos terceras partes de los pacientes que están sostenidos por un respirador artificial durante un coma de por lo menos seis horas de duración habrán muerto en el plazo de un mes, no obstante haberse usado toda la tecnología; asimismo, un seis por ciento podrá permanecer en estado vegetativo persistente.

El bioquímico y neurólogo norteamericano Elie Shneour decía: "Nuestra sociedad moderna ha hecho de la muerte una tragedia porque no sabemos comportarnos con ella (...). La evitamos. Retiramos a los moribundos del mundo de los vivos, lo que es una de las cosas más crueles que podemos hacer. Los "encerramos" en los hospitales y los acorazamos de aparatos. Los aplastamos bajo nuestra tecnología inhumana y, peor aún, los olvidamos".

\section{FUENTES:}

* Constitución Política de Colombia.

* Código de Ética Médica, Ley 23 de 1981.

* Proceso Evolutivo de la Muerte, Jorge Núñez de Arco, Editorial GTZ, 2005.

* Carta Encíclica Evangelium Vitae, Juan Pablo II, Marzo 25 de 1995

* MorirBien, IsaFonnegra de Jaramillo,EditorialPlaneta, 2006

* Dejar Morir No Es Matar; Doctor, ¡déjeme morir!; Entre la Eutanasia y la Distanasia; ¡Morimos por partes! Alfonso * Llano Escobar, S.J., tomado de la Columna Un Alto en el Camino del periódico El Tiempo.

* Derechos del Paciente Terminal, Fundación Proderecho a Morir Dignamente DMD.

* El Neurocirujano ante el debate actual sobre la Muerte Encefálica, Ricardo Hodelín Tablada, Hospital Provincial Clínico Quirúrgico "SATURNINO LORA", Santiago de Cuba. * Alocución del Papa Pio XII ante el Congreso Internacional de Anestesiólogos, La Prolongación de la Vida, Tomado De El Papa Habla, Vol. 4 No. 4, 1958

* Muerte Clínica, Muerte Somática y Muerte Encefálica., José J. Jaramillo-Magaña, Sociedad Mexicana de Anestesiología.

* Consideraciones histórico-culturales y éticas acerca de la muerte del ser humano, María del Carmen Amaro Cano, Revista Cubana de Salud Pública, 2005.

* Declaración sobre la eutanasia de la Sociedad Española de Cuidados Paliativos, Madrid, 2002. 